\title{
Young Adult Mental Health Difficulties: Obstacles to Seeking Help
}

Rosemarie B. LaVilla 


\section{Abstract}

The practice topic considered in this paper is the obstacles preventing young adults from seeking help for mental health difficulties. Research methods include qualitative and quantitative studies primarily collected from college students within the last twelve years. Results show stigma, both perceived and selfheld, are significant factors hindering young adults from seeking help for mental health difficulties. Other factors that hinder help-seeking are: personal characteristics, lack of coping skills, lack of knowledge of services available, and the fear of being labeled. The general conclusions are that with the steady rise in numbers of those suffering with mental health difficulties, it is essential work be done to reduce stigma primarily through education and awareness.

\section{Practice Area}

The population looked at for this area of practice are young adults, specifically young adults with mental health difficulties and what hinders them from help-seeking. The number of young adults suffering from mental health difficulties is at an all-time high in our country and continues to escalate steadily. Many of these young adults are college students, and due to the convenience of access, they are the main source of research studies. Researchers state, "the number of students in higher education experiencing mental health problems is increasing," (Quinn, Wilson, MacIntyre, and Tinklin, 2009, p. 405). These individuals face obstacles like stigmatization (Storrie, Ahern, \& Tuckett, 2010), which play a large role in hindering them from seeking help (Eisenberg, Downs, Golberstein, \& Zivin, 2009). Schoollevel stigma is found to be a problem since it is "negatively associated with medication use, counseling and therapy visits, and to a lesser degree, informal support" (Gaddis, Ramirez, \& Hernandez, 2018, p. 183). Young adults with mental health difficulties are understandably fearful of rejection, and therefore are discouraged from seeking help. Much research demonstrates that individuals identified as having mental health difficulties are viewed as dangerous (Phelan \& Basow, 2007). Identifying the greatest obstacles to help-seeking is relevant in order to assist young adults with mental health difficulties in overcoming these barriers. With this information, efforts can then be made to target the source and provide education and increase awareness of mental health problems.

\section{Research Question}

What hinders young adults from seeking help for mental health difficulties?

\section{Search Methods}

Articles for this literature review were found using the Texas Christian University (TGU) library database and Google Scholar. Articles were gathered on the topic of obstacles to young adults seeking help for mental health difficulties, by searching the key phrases: "Mental health difficulties obstacles help seeking young adults," "hindrance seeking help mental health difficulties young adults," "young adult mental illness obstacles seeking help," "stigma college students mental health issues help seeking," and 
"hindrances mental health difficulties help seeking college students." Search settings were limited to peerreviewed journal articles within the last 15 years.

Most secondary sources in this paper were published within the last 15 years and covered mental health difficulties for young adults and college age students. Some articles were included that did not focus primarily on the target population, but were chosen for additional insights and information on barriers to help-seeking. For example, one article presented results of information from a gathering of 30 researchers studying mental illness self-stigma and future priorities (Lucksted, \& Drapalski, 2015).

\section{Description of Articles}

Various research designs are utilized in this study to determine the obstacles of help-seeking for young adults with mental health difficulties. Some of the methods used are surveys, interviews, focus groups, literature reviews, and electronic databases. These sources provide both qualitative and quantitative data results. Sample size in the studies ranged from 23 participants to over 90,000 participants. Approximately 2/3 of the research focused on young adults with mental health difficulties and the remaining studies included individuals 18 and older. Similarities such as stigma being directly related to barriers experienced by individuals were evident in all but one study, as well as differences found determining the role stigma plays in hindering help-seeking.

\section{Similarities}

10 out of 11 articles supported the idea that the stigmatization of mental health difficulties is the number one obstacle to help-seeking for young adults with mental health difficulties. For example, research shows stigma to be a significant problem for those with depression and hinders seeking help from informal and professional sources (Barney, Griffiths, Christensen, \& Jorm, 2009). It is also evident in the results that prove fear of being discriminated against decreases individuals' readiness to seek help (Schomerus, \& Angermeyer, 2008).

A second similarity found in the articles is that self-stigmatization rather than the perceived stigmatization of others is what most hinders people with mental health difficulties from seeking help. Out of the 11 articles reviewed, 9 showed evidence that this is the case. For example, one study shows that personal stigma regarding seeking professional psychiatric help is a stronger hindrance to seeking help than concern over what others think (Schomerus, Matschinger, \& Angermeyer, 2009). A second study concludes an individual's perception of oneself as a person seeking help affects their readiness and attitude towards seeking support or help (Lucksted, \& Drapalski, 2015).

\section{Differences}

Research design amongst the studies is one area of great difference. Multiple types of surveys were conducted. For example, one research study conducted the survey over the phone (Schomerus et al., 2009). Other researchers collected data from web-based surveys, while another study had individuals show up at a designated location to participate in an online survey (Phelan \& Basow, 2007). Other types 
of methods included literature reviews done by searching databases (Storrie et al., 2010) and conducting a meeting of 30 researchers on the topic to gather together to discuss their research studies and articles (Clement et al., 2015). Other research designs include personal interviews and focus groups.

A second difference that stood out in the literature reviewed was a study showing results that stigma was not the highest ranked barrier to individuals suffering from mental health difficulties. Instead, researchers found that stigma ranked fourth and that fear of disclosure was the most reported barrier to help-seeking (Clement et al., 2015).

Finally, a difference in the studies worth noting is the sample size. One study in Scotland had 12 participants that were interviewed (Quinn et al., 2009). In contrast, one researcher gathered information from over 60,000 online survey participants (Gaddis et al., 2018), and another study accessed over 90,000 participants through a database search covering a 30-year time span (Clement et al., 2015).

\section{Review of Results}

As stated earlier in this paper, research proves stigma, both perceived and self-held, are significant factors that hinder young adults from seeking help for mental health difficulties. Understanding the most common hindrance is vital in order to assist young adults with mental health difficulties in overcoming obstacles with help-seeking. With this information, efforts can then be made to target the identified source and increase help-seeking behaviors of those suffering from mental health problems. Three themes occurring throughout literature reviewed are the influence of self-held stigma on help-seeking, fear of experiencing discrimination as barrier to seeking help, and decrease of stigmatization to increase help-seeking readiness.

\section{Influence of Self-Stigmatization on Help-Seeking}

Research shows self-stigmatization has the greatest influence in preventing young adults with mental health difficulties from seeking help (Gaddis et al., 2018). The young adult population with self-held stigma towards mental health difficulties are particularly unlikely to seek help (Biddle, Donovan, Sharp, \& Gunnell, 2007). This is a significant problem because it keeps individuals from seeking support and help from informal and professional sources (Barney et al., 2009). As mentioned earlier, research proves that self-stigmatization regarding seeking professional psychiatric help is a stronger hindrance to helpseeking than fear of what others think (Schomerus et al., 2009). Another example is how an individual's view of oneself as a person seeking help impacts their attitude and likeliness to seek support or help (Lucksted, \& Drapalski, 2015).

\section{Fear of Discrimination a Barrier to Seeking Help}

Studies provide evidence that young adults hesitate to disclose mental health difficulties on college applications out of fear they may be discriminated, creating a barrier to help-seeking (Lucksted, \& Drapalski, 2015). There is also a barrier created from the fear of being labeled and discriminated against due to a mental illness (Storrie et al., 2010) or even being perceived as dangerous (Phelan \& Basow, 
2007). For example, one study showed that $34 \%$ of participants would not allow someone who saw a psychiatrist to watch their children (Schomerus et al., 2009). Several studies revealed results reflecting fear of disclosure. Another study concluded it was fear of discrimination and disclosure concern that was the most commonly reported hinderance to help-seeking and not stigmatization (Clement et al., 2015). Additionally, yet another study found a general reluctance among young adults to disclose mental health difficulties (Quinn et al., 2009).

\section{Decrease of Stigmatization to Increase Help-Seeking Behavior}

Efforts to decrease the stigmatization shown toward young adults with mental health difficulties and increase help-seeking behavior is a continual theme found in this literature review. Reducing stigma, especially self-held stigma, will help more young adults seek help for mental health difficulties (Eisenberg et al., 2009). This ideology is shown in another research study that concludes that both reduced self-stigmatization and the belief in the effectiveness of professional help will increase readiness and encourage others to engage in help-seeking behavior (Schomerus, \& Angermeyer, (2008). Providing individuals who suffer with mental health difficulties with tools to decrease self-stigmatization is suggested by researchers to be a strategic way to increase help-seeking behavior (Lucksted, \& Drapalski, 2015).

\section{Discussion}

\section{Practice Implications}

Practice implications for applying these findings are to focus on reducing mental health difficulty stigma, specifically self-held stigma, in order to increase young adults' help-seeking efforts (Eisenberg et al., 2009). Equipping these individuals with tools to decrease personally held stigma (Lucksted, \& Drapalski, 2015) and educating them about mental health conditions, will also reduce stigma and increase help-seeking behavior (Phelan \& Basow, 2007).

\section{Future Directions}

More research is needed on the barriers to seeking help experienced by young adults with mental health difficulties who are not college students. Also, there is much research done on more severe mental health conditions such as bipolar disorder and alcohol dependency, but little on health conditions such as depression (Lucksted, \& Drapalski, 2015) as well as why these individuals discontinue treatment (Lucksted, \& Drapalski, 2015). I would like to learn more about these areas of practice. 


\section{References}

Barney, L. J., Griffiths, K. M., Christensen, H., \& Jorm, A. F. (2009). Exploring the nature of stigmatizing beliefs about depression and help-seeking: implications for reducing stigma. $B M C$ public health, 9(1), 61. https://doi.org/10.1186/1471-2458-9-61

Biddle, L., Donovan, J., Sharp, D., \& Gunnell, D. (2007). Explaining non-help-seeking amongst young adults with mental distress: A dynamic interpretive model of illness behavior. Sociology of health $\mathbb{E}^{\circ}$ illness, 29(7), 983-1002. https://doi.org/10.1111/j.1467-9566.2007.01030.x

Glement, S., Schauman, O., Graham, T., Maggioni, F., Evans-Lacko, S., Bezborodovs, N., ... \& Thornicroft, G. (2015). What is the impact of mental health-related stigma on help-seeking? A systematic review of quantitative and qualitative studies. Psychological medicine, 45(1), 11-27. https://doi.org/10.1017/S0033291714000129

Eisenberg, D., Downs, M. F., Golberstein, E., \& Zivin, K. (2009). Stigma and help seeking for mental health among college students. Medical Care Research and Review, 66(5), 522-541. https://doi. org/10.1177/1077558709335173

Gaddis, S. M., Ramirez, D., \& Hernandez, E. L. (2018). Contextualizing public stigma: Endorsed mental health treatment stigma on college and university campuses. Social Science E Medicine, 197, 183191. https://doi:10.1080/15332985.2017.1302039

Lucksted, A., \& Drapalski, A. L. (2015). Self-stigma regarding mental illness: Definition, impact, and relationship to societal stigma. Psychiatric Rehabilitation fournal, 38(2), 99-102. https://doi. org/10.1037/prj0000152

Phelan, J. E., \& Basow, S. A. (2007). College students' attitudes toward mental illness: An examination of the stigma process 1. Journal of Applied Social Psychology, 37(12), 2877-2902. https://doi. org/10.1111/j.1559-1816.2007.00286.x

Quinn, N., Wilson, A., MacIntyre, G., \& Tinklin, T. (2009). 'People look at you differently': Students' experience of mental health support within higher education. British fournal of Guidance $\mathcal{E}^{2}$ Counselling, 37(4), 405-418. https://doi.org/10.1080/03069880903161385

Schomerus, G., \& Angermeyer, M. C. (2008). Stigma and its impact on help-seeking for mental disorders: What do we know? Epidemiology and Psychiatric Sciences, 17(1), 31-37. https://doi. org/10.1017/S1121189X00002669 
Schomerus, G., Matschinger, H., \& Angermeyer, M. C. (2009). The stigma of psychiatric treatment and help-seeking intentions for depression. European Archives of Psychiatry and Clinical Neuroscience, 259(5), 298-306. https://doi.org/10.1007/s00406-009-0870-y

Storrie, K., Ahern, K., \& Tuckett, A. (2010). A systematic review: Students with mental health problems - a growing problem. International Journal of Nursing Practice, 16(1), 1-6. https://doi. org/10.1111/j.1440-172X.2009.01813.x 